\title{
VALIDATING THE SOIL VULNERABILITY INDEX FOR A CLAYPAN WATERSHED
}

\author{
Robert Chan ${ }^{a}$, Claire Baffaut $^{\mathrm{b},{ }^{*}}$, Allen Thompson $^{\mathrm{a}}$, and John Sadler ${ }^{\mathrm{b}}$
}

\begin{abstract}
Assessment studies of conservation efforts have shown that best management practices were not always implemented in the most vulnerable areas where they are most needed. While complex computer simulation models can be used to identify these areas, resources needed for using such models are beyond reach for most water resources managers. Soil and water conservationists need simple, spatially explicit tools such as the USDA-NRCS's Soil Vulnerability Index (SVI) to evaluate the inherent vulnerability of soils and the risk they pose to water quality when used for row crop agriculture. In this study, the SVI was evaluated in the Goodwater Creek Experimental Watershed (GCEW), a claypan watershed in Missouri, using three methods: professional judgement, comparison to the Conductivity Claypan Index (CCI) developed specifically for claypan soils, and comparison to model results. Factors affecting the critical
\end{abstract}


21 areas identified by each method were assessed and classified areas were compared. Slope and

22 depth to claypan had the most variability in GCEW and were found to be influential in

23 determining area classification by each index. While the original definition of SVI included the

24 soil type representative slope from the USDA SSURGO database, slope values provided by a

25 Digital Elevation Model (DEM) improved the index usefulness by classifying visibly degraded

26 and non-degraded areas in different categories. High and moderately high vulnerability areas

27 identified with SVI, $\mathrm{CCl}$ and model results with DEM slopes were consistent and matched

28 professional judgement. Additional testing of SVI is recommended in areas characterized by

29 soils of different permeability and under different climates.

$30 \quad 1$

31 1. Introduction

Non-point source (NPS) pollution from agricultural activity is a major problem in the

33 United States (Shortle et al., 2012). Common pollutants include nutrients such as phosphorus

34 (P) and nitrogen (N), pesticides and herbicides, and sediment. Pollutants are typically

35 transported away from fields via surface runoff or leaching, leading to downstream problems

${ }^{1}$ Abbreviations: CCl: Conductivity Claypan Index, CD: Depth to claypan, DEM: Digital Elevation Model, GCEW: Goodwater Creek Experimental Watershed, HRU: Hydrologic Response Unit, KSAT: hydraulic conductivity, NPS: Non-point source, NRCS: Natural Resources Conservation Service, SL: Slope, SSURGO: Soil Survey Geographic Database, SVI: Soil vulnerability Index, SWAT: Soil and Water Assessment Tool, USDA: US Department of Agriculture. 
36 such as contamination of drinking water, damage to aquatic ecosystems, and sedimentation

37 (Baker, 1992). The transported pollutants also affect farmers in the form of lost inputs that can

38 affect future crop yields.

Use of conservation practices in the U.S. became more prevalent after the Dust Bowl crisis of the 1930's led to the government taking a more active role in soil conservation and

41 related activities (Baveye et al., 2011). At the time, the focus for implementing conservation

42 practices was more reducing soil erosion than reducing agricultural pollution, an additional

43 focus of current policy. Since then, the goal has also included protecting streams and water

44 bodies downstream of agricultural areas from the negative effects associated with agricultural

45 NPS pollution through the use of grassed waterways, contour farming, buffer strips,

46 conservation tillage, and nutrient management plans among other best management practices.

$47 \quad$ Despite billions of dollars spent on conservation programs and a large increase in

48 funding in the 2002 farm bill, skepticism has been expressed by many about the environmental

49 benefits obtained from additional funding allocated to conservation programs, and especially

50 obtained at watershed and regional scales (Mausbach and Dedrick, 2004). Research has

51 typically shown conservation practices to be effective in reducing NPS pollution at field scales

52 (Jokela et al., 2004; Sharpley et al., 2006; Nangia et al., 2010; Douglas-Mankin et al., 2013). In

53 contrast, effectiveness in reducing NPS pollution in larger watersheds has been found to be

54 minimal (Park et al., 1994; Inamdar et al., 2002; Chaubey et al., 2010; Tomer and Locke, 2011).

55 One potential reason is that conservation practices have not been targeted to critical areas that

56 contribute the most contaminants to receiving water bodies (Gale et al., 1993, Strauss et al., 
57 2007; Tomer and Locke, 2011). It is therefore very important that these critical areas are

58 identified.

59 Modeling, indices, and geographic information systems (GIS) can be used to identify and

60 delineate critical areas (Meals et al., 2012). The Agricultural Policy Environmental eXtender

61 (APEX) model is a field scale hydrologic model that can simulate a variety of management

62 operations (Gassman et al., 2010) and has been used to identify critical areas for sediment,

63 runoff, and atrazine in a field located in Northeast Missouri (Mudgal et al., 2012). The Soil and

64 Water Assessment Tool (SWAT) model is a watershed scale model that has also been used,

65 sometimes in combination with APEX, to quantify contaminant delivery to a water body and

66 identify the critical areas (Srinivasan et al., 2005; Busteed et al., 2009; White et al., 2009;

67 Douglas-Mankin et al., 2010; Ghebremichael et al., 2010; Rabotyagov et al., 2014; White et al.,

68 2014). These models are complex and analyses using these tools require significant resources

69 that are beyond those of a state, county, or other local resource management authority. Thus

70 tools that are simpler to implement within a GIS platform are being considered for local or

71 regional analyses.

72 The phosphorus index (PI) and topographic wetness index (TWI) are examples of index

73 approaches to identifying critical areas. The PI is used to assess phosphorus losses at a field

74 level (Lemunyon and Gilbert, 1993). The TWI identifies areas in a watershed where saturation

75 excess overland flow is likely to occur by estimating the saturation potential of soils (Beven and

76 Kirkby, 1979). Methods based on GIS technology are often used in conjunction with modeling

77 or index methods to display critical areas on watershed maps (Hamlett et al., 1992; Tim et al.,

78 1992). Zollweg et al. (1995) demonstrated the use of a GIS-based tool to identify critical areas 
79 responsible for a majority of phosphorus loss in a studied watershed, and Nelson et al. (2011)

80 combined GIS technology with a model based on the Revised Universal Soil Loss Equation

81 (Revised USLE) to identify critical areas for soil loss in a watershed in Kansas.

82 The Soil Vulnerability Index (SVI) was developed by the NRCS as part of the CEAP

83 cropland study (USDA-NRCS, 2012) to rank soils nationwide in terms of their inherent

84 vulnerability to contaminant transport by surface runoff or by leaching when cropped.

85 Vulnerability to contaminant transport by surface runoff was determined based on soil

86 properties that were found to promote surface runoff and erosion, while vulnerability to

87 contaminant transport by leaching was based on soil properties found to promote infiltration.

88 No consideration is given to vegetation or management. Relevant soil properties were

89 determined based on APEX model results for sediment and nutrient losses by surface runoff

90 and percolation in the Upper Mississippi River Basin (USDA-NRCS, 2012). The model was run for

91 a subset of the National Resources Inventory cropland sites throughout the Upper Mississippi

92 River Basin, using the NRCS soil survey database, a climate database, and operator surveys

93 about land management. Each site was ranked as having high, moderately high, moderate, or

94 low soil erosion or nutrient loss, and nitrogen leaching potential based on its output of

95 sediment and nutrient yield and percolation. With all sites ranked, soil properties that

96 correlated well with the risk classes were determined. Hydrologic soil group, erodibility factor,

97 and slope were the top properties for surface runoff and soil erosion, while the same properties

98 plus coarse fragment content were the top properties found to affect infiltration and

99 contaminant leaching. Ranges of values for slope, erodibility factor, and coarse fragment 
101 classify areas into different vulnerability classes. The final ranking criteria were then used to

102 classify all soils within the U.S. so that regional comparisons could be conducted (USDA-NRCS, 103 2012).

104 Compared with using models, using indices to identify critical areas can be a simpler 105 approach requiring fewer input parameters and less preparatory work such as model 106 calibration. However, indices do need to be validated before they can be used to make

107 decisions on conservation efforts. Validation of the SVI within and outside the Upper Mississippi

108 River Basin is necessary before this index is widely used to guide policy. The overall goal of this 109 study was to validate the SVI within the Goodwater Creek Experimental Watershed (CGEW), a

110 Missouri watershed where contaminant transport has been monitored and simulated in detail

111 (Blanchard and Donald, 1997; Donald et al., 1998; Lerch et al., 2011; Baffaut et al., 2015b). The

112 dominance of soils with a restrictive layer causes a high potential for surface runoff and

113 transport of sediment and nutrients to water bodies, and makes this watershed a good

114 candidate for validation of a targeting index. The specific study objectives were to 1) evaluate

115 the ability of the SVI to classify critical areas in terms of vulnerability to contaminant transport

116 by surface runoff in the GCEW, and 2) assess how input parameters used by the SVI affect

117 vulnerability classifications in this watershed. The evaluation was based on professional

118 judgement, comparison with another targeting index developed specifically for soils with a 119 restrictive layer, and comparison with the results of a hydrologic model. 


\section{Materials and methods}

\subsection{Study area}

The Goodwater Creek Experimental Watershed (GCEW; Sadler et al., 2015b) is in Major

123 Land Resource Area 113, Central Claypan Areas (Fig.1): 4 Mha of primarily agricultural land use

124 that cover a portion of Missouri and Illinois and where claypan soils dominate (USDA-SCS,

125 1981). Claypan soils are characterized by a shallow, low permeability clay layer, the claypan,

126 that limits percolation and available water capacity, resulting in a high potential for surface

127 runoff and other surface runoff induced problems. Excessive soil erosion and herbicide

128 transported in surface runoff are known problems throughout the region (Lerch et al., 2008).

129 The GCEW itself covers $72 \mathrm{~km}^{2}$ in Boone and Audrain County in Missouri. Long-term (1970-

130 2010) data from a weather station and a network of rainfall gauges in the watershed show

131 annual precipitation ranging from $569 \mathrm{~mm}$ to $1620 \mathrm{~mm}$, averaging $981 \mathrm{~mm}$ per year (Sadler et

132 al., 2015a). Average annual air temperature was $12{ }^{\circ} \mathrm{C}$, ranging from a January average of -

$1332.7^{\circ} \mathrm{C}$ to a July average of $25.0^{\circ} \mathrm{C}$ (Sadler et al., 2015a). Over the same period, average annual

134 discharge per unit area was $310 \mathrm{~mm}$, or $32 \%$ of the average annual precipitation (Baffaut et al., 135 2015a).

\subsection{SVI Vulnerability Classification}

Risk classification for the SVI was based upon criteria specified by the USDA-NRCS (2012)

138 shown in Table 1, which are based on soil hydrologic group, USLE soil erodibility (K-factor), and 139 slope information for each SSURGO soil polygon in the watershed. Inputs were processed using 140 ArcMap resulting in maps showing risk classifications throughout the GCEW. 
143 available online at the Geospatial Data Gateway website, http://datagateway.nrcs.usda.gov/

144 (January 2013). The hydrologic soil group status was determined from the Revised USLE,

145 Version 2, Related Attributes report. When the hydrologic group was dependent on the

146 drainage status, soils were assumed to be undrained based on knowledge of the watershed. As

147 a result, all non-floodplain soils in GCEW had a hydrologic soil group D. K-factor values were

148 determined from the surface layer Kw values in the Physical Soil Properties report. Slopes

149 values were the representative slope value of each soil type (Lee Norfleet, USDA-NRCS,

150 personal communication, 10 July 2012). As an alternative to representative slope values,

151 vulnerabilities were also calculated based on slopes derived from a $10-\mathrm{m}$ digital elevation

152 model (DEM).

\subsection{SVI evaluation}

Index validation can involve professional judgement, comparison with other indices,

155 comparison with field data, or comparison with results from well calibrated models (Tomer et

156 al., 2003; Dosskey et al., 2011; Chan et al., 2013; Dosskey et al., 2013). In this study, the SVI was

157 validated using professional judgement, comparison with the conductivity claypan index (CCl, a

158 risk assessment index developed specifically for soils with a restrictive layer, Mudgal et al.,

159 2012), and comparison with modeling results.

160 2.3.1. Professional judgement 
Professional judgement is a subjective method. In this case, the extent of the critical

162 areas and their characteristics were critically assessed. In addition, 2009 aerial photos (obtained

163 from Google Earth) of an area known for its poor management at the time were overlaid with

164 the map of critical areas determined with the SVI. Because of the poor management, soil

165 degradation was clearly visible and the quality of the match was visually assessed.

166 2.3.2. Comparison with $\mathrm{CCl}$

\subsubsection{1. $\quad \mathrm{CCl}$ vulnerability classification}

An index called the Conductivity Claypan Index (CCI) was proposed by Mudgal et al.

169 (2012) to rank areas according to their vulnerability to losses by surface runoff in regions

170 dominated by claypan soils. It was developed based on field data obtained in the GCEW.

$171 \mathrm{CCl}$ is based on an equation [Eq. (1)] with inputs of depth to claypan (CD [mm]),

172 saturated hydraulic conductivity of the first soil layer (KSAT [ $\left.\mathrm{mm} \mathrm{h}^{-1}\right]$ ), and slope (SL [\%])

173 (Mudgal et al., 2012).

$174 \quad \mathrm{CCl}=\mathrm{KSAT} * \mathrm{CD} / \mathrm{SL}$

175 The natural logarithm of $\mathrm{CCl}$ was then taken to reduce the magnitude of the values

176 across the watershed and the deviations in the dataset so that it could be classified

177 appropriately. Next, the set of $\ln (\mathrm{CCl})$ values was divided into four groups using the Jenks

178 natural breaks method (Jenks, 1967). This method determines breaks by minimizing variance

179 within groups and maximizing variance between groups (Mudgal et al., 2012). Ranges of In(CCI)

180 values determined for each group were used to define vulnerability levels, with higher values of

$181 \ln (\mathrm{CCl})$ representing lower vulnerability levels. 
183 in order to make valid comparisons with SVI using both sources of slope values. When SSURGO

184 slopes were used, the watershed was divided into polygons based on SSURGO soil type

185 boundaries. When DEM slopes were used, SSURGO soil type boundary polygons were

186 combined with polygons created from the grid of DEM slopes for the watershed, creating

187 smaller polygons within soil type boundaries containing individual DEM slope values.

$188 \quad$ Values of KSAT and CD for each soil type were determined in part from the Physical Soil

189 Properties Report generated from the SSURGO data, downloaded from the Geospatial Data

190 Gateway website, http://datagateway.nrcs.usda.gov/. Values were converted into mm (CD)

191 and $\mathrm{mm} \mathrm{h}^{-1}$ (KSAT) in order to stay consistent with units used in the original development of the

$192 \mathrm{CCl}$. KSAT values for each soil map unit were determined by using the lowest value within the

193 range of saturated hydraulic conductivity values given for the surface horizon of the dominant

194 component of that map unit. Several factors such as land management and landscape position

195 have been shown to significantly affect saturated hydraulic conductivity for claypan soils in

196 central Missouri. Jiang et al. (2007) found that mulch-tilled cropland under a corn-soybean

197 rotation had lower average KSAT compared to hay crop or land in the Conservation Reserve

198 Program. Thus, the lowest value was used for the CCI to reflect typical cropland management

199 throughout the GCEW.

200 Depth to claypan is not part of any SSURGO report or data table. While soil science

201 defines the claypan as a soil layer having close to a doubling in clay content relative to the

202 overlaying layer (Soil Science Glossary Terms Committee, 2008) , CD values for each soil type

203 were assigned based on which soil horizons had saturated hydraulic conductivity values less 
204 than $1 \mathrm{~mm} \mathrm{~h}^{-1}$. Using this method of identifying restrictive layers instead of examining clay

205 content of soil horizons is easier to implement for large study areas and produces results similar

206 to those found using clay content information (not shown). If the low saturated hydraulic

207 conductivity value occurred at the surface horizon, a minimum depth of $50 \mathrm{~mm}$ was assigned. If

208 the low saturated hydraulic conductivity value occurred at a subsequent layer, CD was set equal

209 to the depth to reach the top of the subsequent layer. If no layer for a given soil type was found

210 to have the low saturated hydraulic conductivity value, the depth to the bottom of the last layer

211 was used as CD.

2.3.2.2. Comparison of SVI with $\mathrm{CCl}$ : contingency tables

213 Risk classifications determined by the SVI and CCI were compared based on the

214 watershed area classified in each vulnerability category and on the watershed area that was in

215 agreement or disagreement between indices (contingency tables). In order to focus on

216 comparing the high risk, critical areas, vulnerability classifications compared in contingency

217 tables were reduced to two classes: high vulnerability areas defining one class, designated as

218 "high", and the remaining three categories defining another class, designated "not high".

219 Agreement occurred if each was classified the same (high or not high) by each index while

220 disagreement occurred if areas were classified oppositely by each index. Index classification of

221 critical areas was considered to be the same if the high vulnerability areas agreed with each

222 other according to contingency tables. Two contingency tables were made, one comparing the

$223 \mathrm{SVI}$ and $\mathrm{CCl}$ when SSURGO slopes were used and another comparing them when DEM slopes

224 were used.

$225 \quad$ 2.3.2.3. Variability of input parameters 
227 hydrologic group in SVI and the combination of KSAT and CD both quantify the potential for 228 surface runoff. Similarly, both indices use the slope as an input parameter, which significantly

229 affects erosion process. However, erosion processes are further considered by SVI by including

230 the Universal Soil Loss Equation (USLE) erodibility factor while no similar parameter is

231 considered in CCI. The variability of input parameters throughout the GCEW was represented

232 by the fraction of the watershed having parameter values within a certain range. Regarding

233 slopes, the percentage of watershed area having slope values in specified ranges was

234 determined with both SSURGO and DEM slopes as information source. Similarly, the variability

235 of $\mathrm{CD}, \mathrm{KSAT}$, and hydrologic group and the number of distinct values for these parameters in

236 the watershed was assessed based on their area distribution. Similar analysis was performed

237 for the USLE erodibility factor.

238 2.3.3. Comparison with modeling results

\subsubsection{GCEW SWAT model}

The SWAT model used in this study was the model application parameterized,

241 calibrated, and validated specifically for the GCEW and claypan soil characteristics by Baffaut et

242 al. (2015b). The model was calibrated and validated for flow at a daily time step and loads of

243 atrazine, sediment, and dissolved P at a monthly time step for the years from $1993-2010$.

244 Measured data were obtained from three weirs in the GCEW. Model performance was assessed

245 using the percent bias, the Nash-Sutcliffe efficiency, and the coefficient of determination.

246 Additional details about changes made to the SWAT code to improve the simulation of 
247 percolation processes in claypan soils, about the model parameterization, and about its

248 calibration and validation can be found in Baffaut et al. (2015b).

249 While this SWAT application considered all the significant crops and tillage systems

250 present in the watershed from 1993 to 2010, land management was simplified for this study.

251 The objective here was to evaluate the vulnerability of the land to crop production from the

252 point of view of water quality impacts. For each hydrologic response unit (HRU), the

253 management was set to a 2-year rotation of conventionally tilled corn followed by no-till

254 soybean with no other conservation practices simulated, no matter what the original land use

255 was. This rotation represents the most common practices used by the producers in the GCEW

256 for corn and soybean, which are the most common crops in the watershed. Curve numbers

257 were set to 84 for hydrologic group D soils, and to 80 for hydrologic group C soils. Initial residue

258 amounts were set to $2000 \mathrm{~T} /$ ha for all HRUs. Specific settings used in the management

259 operations schedule can be found in supplemental material for Baffaut et al. (2015b), in a

260 section titled "Field operation scenarios". Other parameters of the model were left to those of

261 the calibrated model.

262 Contaminant loads from HRUs were determined for nitrogen $(\mathrm{N})$, phosphorus $(\mathrm{P})$, and

263 sediment. The model was run with generated weather for 3 years to initialize the state

264 variables followed by 60 years to calculate average annual amounts of organic $N, N$ in surface

265 runoff, $\mathrm{N}$ in lateral flow, organic $\mathrm{P}$, soluble $\mathrm{P}$ in surface runoff, mineral $\mathrm{P}$ attached to sediment,

266 and sediment yield for each HRU. Total $\mathrm{N}$ and P contaminant loads were then calculated by

267 summing $\mathrm{N}$ and $\mathrm{P}$ outputs, and sediment load was determined directly from the sediment yield 268 output. 
271 criteria in Table 1 and Eq. 1. The SVI inputs of slope, hydrologic soil group, and USLE K-factor

272 were determined from the model input data. The slope was the HRU slope value found in the

273 HRU input file, which is calculated by the ArcSWAT interface based on the DEM and the level of

274 discretization used in the model. The hydrologic soil group and USLE erodibility factors were

275 determined from the soil inputs for each HRU and originate from SSURGO data.

276 The $\mathrm{CCl}$ inputs of slope, KSAT, and CD were also determined from SWAT input data.

277 Slope and KSAT were taken directly from SWAT HRU and soil input data, and CD was

278 determined using the method explained previously. With the parameters determined, a soil

279 vulnerability level was assigned to each $\mathrm{HRU}$ by calculating $\ln (\mathrm{CCl})$ values and separating them

280 into groups using the Jenks natural breaks method as described previously.

281 In addition to SVI and CCI vulnerability assessment, HRU vulnerability was assessed

282 using the model outputs. Sediment yields, total N (TN) and total P (TP) loss were classified into

2834 categories (high, moderately high, moderate, and low) using the Jenks natural breaks method 284 with higher losses indicating more vulnerability.

\subsubsection{Evaluation of the SVI}

The SVI was evaluated by two different methods:

287 1. Average sediment, TN and TP loss were calculated for each SVI vulnerability class.

288 Standard deviations were calculated as well to evaluate whether these vulnerability categories 289 coincided well with the expected loss of sediment and nutrients. 
2902 2. Contingency tables were calculated between the number of HRUs classified in each

291 vulnerability class by the SVI and the model. In addition, contingency tables between the CCI

292 and the model were also calculated to understand the differences between the more general

293 SVI index, and the claypan soil specific CCl. These contingency tables were developed on the

294 basis of HRU counts as opposed to watershed area to avoid a distortion of the comparison

295 caused by the fact that all HRUs do not have the same size.

\section{3. RESULTS}

\subsection{Professional judgement evaluation}

Maps of areas classified using the SVI with SSURGO and DEM slope sources (Fig. 2) show

299 that no areas were classified as low vulnerability with the SVI. The level of moderate

300 vulnerability contains the floodplain and soils on the watershed divide. Floodplains in GCEW are

301 characterized by deeper soils, no restrictive layer, and low slope, which together explain their

302 moderate vulnerability. Some vulnerability of these soils stems from the fact that they can be

303 flooded, which is not a consideration factor in the SVI. Currently, these soils are most often

304 associated with grassland or woodland and are only rarely cropped. However, this was not the

305 case in the 1970's when land was cropped all the way to the stream bank. Soils on the

306 watershed divide do have a restrictive layer but the low slope has slowed down erosion from

307 these soils and the claypan is located deeper than on the back slope. Thus, the slope may

308 indirectly reflect the impact of the depth to claypan. 
311 SSURGO representative slopes caused slightly more land to be categorized in this highest class

312 of vulnerability, especially in the upstream part of the watershed. On the other hand, DEM

313 versus SSURGO slopes had a large impact on the moderately high and moderate categories.

314 When SSURGO slopes were used, most of the soils were given a moderately high vulnerability

315 (Fig.2). Unfortunately, this is not very helpful as more than half of the watershed is categorized

316 as such. When used with DEM slopes, the index becomes more powerful with reduced areas of

317 moderately high vulnerability that are adjacent to the high vulnerability areas. These soils are

318 currently cropped, often with significant management practices designed to reduce erosion.

319 However, if best management practices are not implemented (Fig. 3), erosion and soil

320 degradation occurs.

321 On this photo (Fig. 3a), the fields located in the center right are visibly degraded.

322 However, the SVI derived with SSURGO slope classified these fields in the moderately high

323 vulnerability category with very little indication of the highest vulnerability (Fig. 2a). When SVI

324 was calculated with DEM slopes, these fields were clearly targeted with high and moderately

325 high vulnerability (Fig. 3b), and differentiated from the rest, which was then categorized in the 326 moderate vulnerability category.

\section{$327 \quad 3.2$. Comparison of SVI and CCI}

\subsubsection{SVI and $\mathrm{CCl}$ classification}

Table 2 shows the percentage of the watershed classified into each vulnerability class

330 according to the SVI and CCI when SSURGO and DEM slopes are used. Independently of what

331 slope values were used, the $\mathrm{CCl}$ classified about $10 \%$ more of the watershed in the high 
332 vulnerability category and $10-20 \%$ more in the moderately high vulnerability category than did

333 the SVI (Table 2). On the other hand, the CCI classified about half as much area in the moderate 334 vulnerability category compared with the SVI.

335 Similarly to the SVI, the CCl classified the majority of the watershed (62\%) in the 336 moderately high vulnerability category when SSURGO slopes were used. Using DEM slopes in 337 each index resulted in 20-25\% less moderately high vulnerability areas, which were often 338 classified instead in the moderate vulnerability category (Table 2). Using the resolution of the 339 10-m DEM brings additional power to these indices for targeting conservation efforts and the 340 rest of this analysis will concentrate on only results obtained with DEM slopes.

341 The map of CCl categories when DEM slopes were used (Fig. 4) showed that when 342 compared to SVI calculated with DEM slopes (Fig. 2b), CCI produced more high vulnerability 343 land (Table 2 ) but that land was roughly located in the same areas. The additional land in the $344 \mathrm{CCl}$ highest vulnerability class included some of the land that was in the moderately high

345 vulnerability category with SVI. The moderately high vulnerability category became much larger 346 taking some of the land that was classified in the moderate vulnerability category with SVI.

347 Table 3 shows the contingency table resulting from comparing SVI and CCI vulnerability

348 classifications with DEM slopes. Low, moderate, and moderately high vulnerability areas were 349 merged into a single class referred to as not high, while the "high" class contains high

350 vulnerability areas. Reading diagonally from the top left to the bottom right shows the

351 percentage of watershed area with map classifications that agreed, while the other diagonal 352 shows the percentage of classifications that disagreed. 
354 watershed. However, it should be remembered that the not high category includes moderately

355 high, moderate, and low vulnerability areas and this result doesn't necessarily mean that index

356 classifications agreed for such areas. Isolating high vulnerability areas in this analysis allowed

357 index classifications of these areas to be compared. Indices agreed about classification of high

358 vulnerability areas for $5.3 \%$ of the watershed. Comparing these numbers to the percentage of

359 watershed area classified into the high vulnerability risk class by the SVI (Table 2) shows that

360 the SVI and CCI agreed for the majority of these areas. Even though the SVI didn't classify as

361 many areas in the high vulnerability category as the $\mathrm{CCl}$ did, this gives confidence about the

362 ones it did. Most disagreement occurred between areas classified as high vulnerability by the

$363 \mathrm{CCl}$ but some other vulnerability level by the SVI. Very little (1.1\% of the watershed area) was

364 put in a different category by $\mathrm{CCl}$.

3.2.2. Variability of Input Parameters

Among the SVI input parameters, there was no variability in the hydrologic soil group

367 parameter for the upland soils, and variability in the K-factor parameter didn't lead to any

368 variation in watershed vulnerability classifications. Hydrologic soil group was D for all upland

369 soil types in the watershed ( $92 \%$ of the watershed area). Among the flood plain soils, Wilbur,

370 Twomiles, and Moniteau silt loam soil series were classified in the hydrologic group C or B when

371 drained but in group D when undrained as is assumed in this study. Only the Belknap soil series

372 were classified in the soil hydrologic group C. All values of $\mathrm{K}$-factor were greater than or equal 
373 to 0.32 , and combined with all soil types having hydrologic soil group $D$, did not cause any areas

374 to be classified differently by the SVI (Table 2).

375 Table 4 shows the distribution of SSURGO and DEM slopes found in the GCEW. DEM

376 slopes had a larger percentage of slopes in the $0-1 \%$ and $>4 \%$ ranges than did SSURGO slopes,

377 while SSURGO slopes had a greater percentage of slopes in 1-2\% and $2-4 \%$ ranges.

379 by the same indices using different slope sources (Table 2), the differences between the 380 distribution of SSURGO and DEM slopes in different slope ranges reflects how percentages of 381 vulnerability classifications change as different slope sources are used in the SVI and CCI. When

382 DEM slopes were used, each index found a larger percentage of high vulnerability areas and a

383 larger percentage of moderate and low vulnerability areas reflecting the greater percentage of

384 slopes in the $0-1 \%$ and $>4 \%$ ranges for DEM slopes. Percentages of watershed area in the

385 moderately high vulnerability class, as seen in Table 2, increase when SSURGO slopes are used.

386 This result reflects the larger percentage of slopes in the $2-4 \%$ range using SSURGO slopes.

387 Additional CCl inputs were CD and KSAT. There was little variation in KSAT values with all 388 soils having a KSAT of $14.4 \mathrm{~mm} \mathrm{~h}^{-1}$ except for Leonard silty clay loam, which had a KSAT of 5.04

$389 \mathrm{~mm} \mathrm{~h}^{-1}$. In contrast, there were large differences in CD (Fig. 5). While most (68\%) of the

390 watershed had soils with a restrictive layer between 50 and $100 \mathrm{~cm}$, about $14 \%$ of the

391 watershed had a restrictive layer within the first $50 \mathrm{~cm}$, and another $18 \%$ of the watershed had

392 either no restrictive layer or it was found deeper than $1 \mathrm{~m}$. This last group of soils contained the 393 floodplain soils, characterized by poor drainage when undrained and frequent flooding 
394 occurrences. In spite of these variations of CD, all these soils were classified as poorly drained

395 and were in the hydrologic soil group D when undrained. Thus, the use of CD instead of soil

396 hydrologic group provides additional opportunities to differentiate runoff potential within the

397 soils of this watershed.

398

\subsection{Comparison to SWAT model results}

\subsubsection{Contaminant loss by SVI vulnerability class}

Table 5 shows the average values and standard deviations of sediment, TN, and TP loss

402 by SVI vulnerability level. These classes were very well defined by the loss values, with low 403 variability within each class, as indicated by the standard deviation. Mean sediment loss

404 decreased by half for each vulnerability class. $\mathrm{N}$ and $\mathrm{P}$ losses for each class were about $70 \%$ and

$40560 \%$, respectively, of those from the class directly above. SVI vulnerability categories

406 corresponded to significant differences in sediment and nutrient loss, as predicted by this SWAT

407 model.

\subsubsection{Contingency tables between $\mathrm{SVI}$, model results, and $\mathrm{CCl}$}

409 Table 6 shows the contingency table between the HRUs classified in each vulnerability

410 class by the SVI and using model results. Tables for sediment, TN, and TP are very similar.

411 Overall, results indicate 75\% agreement between the SVI and the SWAT model results in terms

412 of number of HRUs, which translates into $73 \%$ agreement in terms of watershed area for

413 sediment and TP, and 86\% for TN. There was especially good agreement of classification for 
414 those HRUs given a high or moderately high vulnerability with SVI. The largest source of

415 disagreement was found among HRUs classified in the moderate vulnerability class by SVI:

416 almost a third of those had low sediment, TN, and TP loss according to SWAT results. Those

417 correspond to Putnam and Adco soils (hydrologic soil group D) on land with a slope less than

$4181 \%$. The vulnerability level given by SVI to these soils is moderate because their soil erodibility is

419 greater than 0.28. However, the low slope caused lower simulated sediment and nutrient

420 yields, which caused these HRUs to be classified in the lowest category by the model results.

421 This problem does not occur with the classification made using $\mathrm{CCl}$ : these $40 \mathrm{HRUs}$ end up in

422 the lowest category of vulnerability both with $\mathrm{CCl}$ and using SWAT simulated sediment yields

423 (Table 7).

$424 \quad$ There was some discrepancy between $\mathrm{CCl}$ and SWAT sediment yields in the highest

425 categories of vulnerability. The five high sediment and nutrient producing HRUs, according to

426 SWAT simulated results and to SVI, are given only a moderate vulnerability level by $\mathrm{CCl}$. These

427 HRUs all have a high slope and correspond to Leonard soils, soils that are classified in the soil

428 hydrologic group D because of the low saturated conductivity of the least transmissive layer

429 and the shallow depth of this least transmissive layer. This poor drainage and the high slope

430 produce a high vulnerability level as shown by SVI and by the simulated sediment and nutrient

431 losses. However, these characteristics do not meet the definition of a claypan soil and the high

432 vulnerability is not picked up by $\mathrm{CCl}$ because the depth to claypan is set to the profile depth. 


\section{4. DISCUSSION}

\subsection{Discrepancies caused by the resolution of the slope map}

436 moderately high vulnerability areas (from 52 to 24) compensated by an increase in lower

437 vulnerability areas and a small increase in high vulnerability areas. This is an important

438 consideration as moderately high vulnerability areas are likely to be considered as candidates

439 for conservation treatment. In addition, the initial result using SSURGO slopes gave more than

440 half of the watershed a moderately high vulnerability, which is again too large of an area to 441 target for potential conservation efforts.

443 and DEM slopes. Given that all soils in GCEW were in the hydrologic soil group D and that USLE

444 erodibilities were all greater than or equal to 0.32 , the distribution of SVI categories were really

445 equal to the distribution of slopes in the $>4 \%, 2-4 \%, 1-2 \%$, and $0-1 \%$ ranges. Slopes in the $>4 \%$

446 range led to high vulnerability, the 2-4\% range led to moderately high vulnerability, and slopes

$447<2 \%$ led to moderate vulnerability. The differences between SSURGO and DEM slope

448 distributions are reflected in an increase in high vulnerability areas, a decrease in moderately

449 high vulnerability areas, and an increase in moderate vulnerability areas.

450 When considering the benefit of using DEM slopes instead of SSURGO slopes as inputs in

451 these indices, how each slope is determined should be considered. DEM slopes used in these

452 indices were calculated from 10-m digital elevation maps. SSURGO slope values were the 
453 representative value given in the SSURGO database for each soil map unit. The representative

454 slope is calculated as the average of the slopes of all soil polygons found within a map unit

455 (Jorge Lugo-Camacho, USDA-NRCS, personal communication, 8 August 2014). As a result, the

456 SSURGO representative slope values cannot be associated with a particular area or even with a

457 particular size area since the size of each soil map unit varies. However, SSURGO maps were

458 developed at scales ranging from $1: 12,000$ to $1: 63,000$, with most of it being at the $1: 12,000$

459 scale, which corresponds to a smallest delineation of 1.5 ha (USDA-NRCS, 2016). Thus the area

460 represented by each polygon is variable and larger than a $10 \mathrm{~m}$ by $10 \mathrm{~m}$ DEM cell by several

461 orders of magnitude. On the other hand, DEM slopes provide information that is more spatially

462 accurate and that applies to a finer scale. However, using DEM slopes requires more time and

463 computing power than SSURGO slopes. When it is necessary to classify a very large area such as

464 an entire state, the time required in using DEM slopes in an index may not be reasonable and

465 SSURGO slopes could be a better fit. For smaller scales, such as classification of a watershed,

466 the time required isn't as long and DEM slopes could receive greater consideration. In future

467 work using DEM slopes, methods to filter the data removing areas such as roads and determine

468 average field slopes could be examined.

\subsection{Discrepancies caused by the variability of input parameters}

Because there was no variability in hydrologic soil group across the soils of GCEW and

471 variability in K-factor was not affecting vulnerability classifications, slope was the only

472 parameter responsible for changes in the SVI. CCI used the slope, as the SVI did, but instead of

473 the hydrologic soil group, it used CD and KSAT. Hydrologic soil group is determined from the 
474 depth to reach a restrictive layer or high water table and the saturated hydraulic conductivity of

475 the least transmissive soil layer within the depth encompassed by the restrictive layer or high

476 water table (USDA-NRCS, 2009). These characteristics are similar to the CD and KSAT

477 parameters. The depth to reach a restrictive layer is equal to CD in the GCEW, and the

478 saturated hydraulic conductivity of the least transmissive soil layer above the claypan is

479 sometimes equal to KSAT in the GCEW. However, hydrologic soil group doesn't reflect the

480 variability that exists between the different soil map units as much as CD and KSAT can. Among

481 the GCEW soil map units, CD values ranged from $356 \mathrm{~mm}$ to $1651 \mathrm{~mm}$, KSAT values ranged

482 from $2.4 \mathrm{~mm} \mathrm{hr}^{-1}$ to $32.4 \mathrm{~mm} \mathrm{hr}^{-1}$ and the combined CD*KSAT values ranged from 4,060 $\mathrm{mm}^{2}$

$483 \mathrm{hr}^{-1}$ to $16,510 \mathrm{~mm}^{2} \mathrm{hr}^{-1}$.

\subsection{Discrepancies caused by the classification method}

Differences in classification by the SVI and CCI were also caused by the method each

486 uses to classify areas. The SVI uses criteria that always lead to the same vulnerability

487 classification using the criteria shown in Table 1 once parameters are known for a soil. They do

488 not change as a function of the soils present in the study area or of the study area size. This is

489 an advantage when there is a need to be consistent across different areas. Classifications

490 assigned by the $\mathrm{CCl}$, on the other hand, can vary depending on the study area because the $\mathrm{CCl}$

491 uses the Jenks natural breaks method to define the different vulnerability categories across the

492 range of $\mathrm{CCl}$ values calculated for each grid cell. Thus different thresholds between the soil

493 vulnerability categories can occur, based on the sample size and the values of the numbers

494 analyzed. This can be advantageous when there is a need to identify the most vulnerable areas 
495 no matter what the overall vulnerability level is, for example when a given amount of cost share

496 dollars is available and needs to be allocated to the most vulnerable land in a watershed or

497 administrative district.

498 However, the vulnerability levels determined by $\mathrm{CCl}$ can be influenced by the scale of

499 the analysis. When the scale of analysis is changed, variability in soil properties often changes

500 as there is usually more variability for larger areas than for smaller ones. On the other hand,

501 classifications determined by the SVI will not change based on the scale of analysis or amount

502 of variability in input parameters. However, the study area does need to include enough

503 variability in soil properties so that different vulnerability levels can be identified. Otherwise,

504 there is the possibility that SVI would determine all areas to be of the same vulnerability level.

\section{5. CONCLUSIONS}

In this study the SVI was used with SSURGO and DEM slope sources to classify areas for

507 their inherent vulnerability to contaminant transport by surface runoff in a Missouri claypan

508 watershed. Watershed vulnerability classification was compared to the classification produced

509 by the $\mathrm{CCl}$, an alternative index designed specifically for claypan soils, and to a classification

510 produced by a SWAT model. The variability of input parameters and its impact on index

511 classification were assessed.

512 Results showed that DEM slopes gave more targeting power to the SVI than SSURGO

513 representative slopes. When used with DEM slopes, the SVI, CCI, and the SWAT model gave

514 similar results. Compared to the SWAT model results, $\mathrm{CCl}$ gave more consistent results for areas

515 of low vulnerability. However, there were inconsistencies between the model results and CCI 
516 for high vulnerability areas due to our criterion defining the depth to claypan. A less

517 constraining criterion may improve results for restrictive layers that are not claypans.

518 Because the SVI category thresholds do not depend on the study area, the SVI is more

519 useful for regional analyses or when consistency of vulnerability categories is needed across

520 several watersheds. The $\mathrm{CCl}$ may be more useful to target conservation efforts in smaller areas

521 where there is less variability of SVI input parameters.

522 In this study, the SVI was evaluated based on the conditions that exist in the GCEW, a

523 fairly homogeneous watershed characterized by claypan soils that were all in the soil hydrologic

524 group D. Because of this characteristic, the primary pollutant transport mechanism was surface

525 runoff. For a complete evaluation and before transfer of these results to other, more complex

526 watersheds, additional testing needs to be considered in areas characterized by soils of varying

527 permeability, which may trigger different hydrologic processes. These evaluations have been

528 initiated for seven additional watersheds throughout the United States. Located in different

529 physiographic regions, these watersheds will also provide opportunities to evaluate the impact

530 of precipitation regimes.

\section{6. ACKNOWLEDGEMENTS}

532 We gratefully acknowledge that partial funding for this research was provided by the 533 USDA-NRCS Conservation Effect Assessment Project (Agreement No. 67-3A75-12-109). 


\section{REFERENCES}

535 Baffaut, C., Sadler, E.J., Ghidey, F., 2015a. Long-Term Agroecosystem Research in the Central Mississippi River Basin: Goodwater Creek Experimental Watershed Flow Data. Journal of Environmental Quality, 44, 18-27.

538 Baffaut, C., Sadler, E. J., Ghidey, F., Anderson, S. H., 2015b. Long-Term Agroecosystem Research in the Central Mississippi River Basin: SWAT Simulation of Flow and Water Quality in the Goodwater Creek Experimental Watershed. J Environ. Qual., 44, 84-96.

541 Baker, L. A., 1992. Introduction to nonpoint source pollution in the United States and prospects for wetland use. Ecol. Eng., 1, 1-26.

543 Baveye, P.C. et al., 2011. From Dust Bowl to Dust Bowl: Soils are Still Very Much a Frontier of 544 Science. Soil Sci. Soc. Am. J., 75, 2037-2048.

545 Beven, K.J., Kirkby, M.J., 1979. A physically based, variable contributing area model of basin $546 \quad$ Hydrology. Bull. Int. Assoc. of Sci. Hydrol., 24, 43 - 69.

547 Blanchard, P.E., Donald, W.W., 1997. Herbicide Contamination of Groundwater Beneath $548 \quad$ Claypan Soils in North-Central Missouri. J Environ Qual, 26, 1612-1621.

549 Busteed, P. R., Storm, D. E., White, M. J., \& Stoodley, S. H., 2009. Using SWAT to target critical 550 source sediment and phosphorus areas in the Wister Lake Basin, USA. Am. J. Environ.

552 Chan, R.E., Thompson, A.L., Baffaut, C., Sadler, E.J., 2013. Evaluating the Soil Vulnerability Index 553 and Conductivity Claypan Index for Claypan Soils in Missouri, ASABE Annu. Int. Meet.

$554 \quad$ ASABE, Kansas City, Missouri, pp. Paper \# 131620723. 
555 Chaubey, I., Chiang, L., Gitau, M.W., Mohamed, S., 2010. Effectiveness of best management

556 practices in improving water quality in a pasture-dominated watershed. J. Soil and

$557 \quad$ Water Conserv., 65, 424-437.

558 Donald, W.W., Hjelmfelt, A.T., Alberts, E.E., 1998. Herbicide Distribution and Variability Across

559 Goodwater Creek Watershed in North Central Missouri. J. Environ. Qual., 27, 999-1009.

560 Dosskey, M.G., Qiu, Z., Helmers, M.J., Eisenhauer, D.E., 2011. Improved indexes for targeting

561 placement of buffers of Hortonian runoff. J. Soil and Water Conserv., 66, 362-372.

562 Dosskey, M.G., Qiu, Z., Kang, Y., 2013. A Comparison of DEM-Based Indexes for Targeting the

563 Placement of Vegetative Buffers in Agricultural Watersheds. J. Am. Water Resour.

$564 \quad$ Assoc., 49, 1270-1283.

565 Douglas-Mankin, K.R., Srinivasan, R., Arnold, J.G., 2010. Soil and Water Assessment Tool (SWAT)

566 Model: Current Developments and Applications. Trans. ASABE, 53, 1423-1431.

567 Douglas-Mankin, K.R., Daggupati, P., Sheshukov, A.Y., Barnes, P.L., 2013. Paying for sediment:

568 Field-scale conservation practice targeting, funding, and assessment using the Soil and

569 Water Assessment Tool. J. Soil and Water Conserv., 68, 41-51.

570 Gale, J. A., et al., 1993. Evaluation of the Experimental Rural Clean Water Program (National

571 Water Quality Evaluation Project. North Carolina State University Water Quality Group,

572 Biological and Agricultural Engineering Department, North Carolina State University.

573 EPA-841-R-93-005). Raleigh, NC: United States Environ. Protection Agency.

574 Gassman, P.W. et al., 2010. The Agricultural Policy/Environmental eXtender (APEX) Model: An

575 Emerging Tool for Landscape and Watershed Environmental Analyses. Trans. ASABE, 53, $576 \quad 711-740$. 
577 Ghebremichael, L. T., Veith, T. L., Watzin, M. C., 2010. Determination of critical source areas for 578 phosphorus loss: Lake Champlain Basin, Vermont. Trans. ASABE, 53, 1595-1604.

579 Hamlett, J.M. et al., 1992. Statewide GIS-based ranking of watersheds for agricultural pollution 580 prevention. J. Soil and Water Conserv., 47, 399-404.

581 Inamdar, S.P., Mostaghimi, S., Cook, M.N., Brannan, K.M., McClellen, P.W., 2002. A long-term, watershed-scale, evaluation of the impacts of animal waste BMPs on indicator bacteria concentrations. JAWRA J. Am. Water Resour. Assoc., 38, 819-833

584 Jenks, G. F.,1967. The data model concept in statistical mapping. International Yearbook of Cartography, 7, 186-190.

586 Jiang, P., Anderson, S.H., Kitchen, N.R., Sadler, E.J., Sudduth, K.A., 2007. Landscape and Conservation Management Effects on Hydraulic Properties of a Claypan-Soil

Jokela, W. E., Clausen, J. C., Meals, D. W., Sharpley, A. N., 2004. Effectiveness of agricultural best management practices in reducing phosphorous loading to Lake Champlain. Lake Champlain: Partnerships and Research in the New Millennium (pp. 39-52): Springer.

592 Lemunyon, J. L., Gilbert, R. G., 1993. The concept and need for a phosphorus assessment tool. J. Production Agriculture, 6, 483-496.

594 Lerch, R.N. et al., 2008. Overview of the Mark Twain Lake/Salt River Basin Conservation Effects Assessment Project. J. Soil and Water Conserv., 63, 345-359.

596 Lerch, R.N., Sadler, E.J., Sudduth, K.A., Baffaut, C., Kitchen, N.R., 2011. Herbicide Transport in Goodwater Creek ExperimentalWatershed: I. Long-Term Research on Atrazine. J. Am. Water Resour. Assoc., 47, 209-22. 
599 Mausbach, M.J., Dedrick, A.R., 2004. The length we go: Measuring environmental benefits of conservation practices. J. Soil and Water Conserv., 59, 96A-103A.

601 Meals, D. W., Sharpley, A. N., Osmond, D. L., 2012. Lessons learned from the NIFA-CEAP: Identifying critical source areas. Raleigh, NC: NC State University. Retrieved from http://content.ces.ncsu.edu/identifying-critical-source-areas.pdf

604

605

606

607

608

609

610

611

Mudgal, A. et al., 2012. Using the Agricultural Policy/Environmental eXtender to develop and validate physically based indices for the delineation of critical management areas. J. Soil and Water Conserv., 67, 284-299.

Nangia, V. et al., 2010. Modeling the field-scale effects of conservation agriculture on land and water productivity of rainfed maize in the Yellow River Basin, China. Int. J. Agricultural and Biological Eng., 3, 5-17.

Nelson, N., et al., 2011. Cheney Lake Watershed: Prioritization of conservation practice implementation. Manhattan, Kansas: Kansas State University Agricultural Experiment Station and Cooperative Extension Service. Retrieved from http://www.ksre.ksu.edu/bookstore/pubs/MF3031.pdf.

Park, S.W., Mostaghimi, S., Cooke, R.A., McClellan, P.W., 1994. BMP Impacts on Watershed Runoff, Sediment, and Nutrient Yields. JAWRA J. Am. Water Resour. Assoc., 30, 10111023.

Sadler, E.J., Sudduth, K.A., Drummond, S.T., Vories, E.D., Guinan, P.E., 2015a. Long-Term Agroecosystem Research in the Central Mississippi River Basin: Goodwater Creek Experimental Watershed Weather Data. Journal of Environmental Quality, 44, 13-17. 
620 Sadler, E.J. et al., 2015b. Long-Term Agroecosystem Research in the Central Mississippi River

621 Basin: Introduction, Establishment, and Overview. J. Environ. Qual., 44, 3-12.

622 Sharpley, A. N., et al., 2006. Best management practices to minimize agricultural phosphorus

623 impacts on water quality (USDA Agricultural Research Service Publication 163).

624 Washington, DC: US Government Printing Office.

625 Shortle, J.S., Ribaudo, M., Horan, R.D., Blandford, D., 2012. Reforming Agricultural Nonpoint

626 Pollution Policy in an Increasingly Budget-Constrained Environment. Environ. Sci. and

627 Technology, 46, 1316-1325.

628 Soil Science Glossary Terms Committee. 2008. Glossary of soil science terms. SSSA, Madison, $629 \quad$ WI.

630 Srinivasan, M.S., Gérard-Marchant, P., Veith, T.L., Gburek, W.J., Steenhuis, T.S., 2005.

631 Watershed scale modeling of critical source areas of runoff generation and phosphorus

632 transport. JAWRA J. Am. Water Resour. Assoc., 41, 361-377.

633 Strauss, P. et al., 2007. Using critical source areas for targeting cost-effective best management 634 practices to mitigate phosphorus and sediment transfer at the watershed scale. Soil Use 635 and Management, 23, 144-153.

636 Tim, U.S., Mostaghimi, S., Shanholtz, V.O., 1992. Identification of critical nonpoint pollution source areas using geographic information systems and water quality modeling. JAWRA J. Am. Water Resour. Assoc., 28, 877-887

639 Tomer, M.D., James, D.E., Isenhart, T.M., 2003. Optimizing the placement of riparian practices 640 in a watershed using terrain analysis. Journal of Soil and Water Conservation, 58, 198641206. 
642 Tomer, M. D., Locke, M. A., 2011. The challenge of documenting water quality benefits of

643

644

645

646

647

648

649

650

651

652

653

654

655

656

657

658

659

660

661

662

663

conservation practices: A review of USDA-ARS's conservation effects assessment project watershed studies. Water Sci. and Technology, 64, 300-310.

USDA-NRCS, 2012. Assessment of the effects of conservation practices on cultivated cropland in the Missouri River Basin. Retrieved from http://www.nrcs.usda.gov/Internet/FSE DOCUMENTS/stelprdb1042093.pdf

USDA-NRCS. (2016). Description of Soil survey geographic (SSURGO) database. Washington, D.C.: USDA Natural Resources Conservation Service. Retrieved from http://www.nrcs.usda.gov/wps/portal/nrcs/detail/soils/survey/geo/?cid=nrcs142p2_05 3627, accessed January 25, 2016.

USDA-SCS, 1981. Land resource regions and major land resource areas of the United States. In Agriculture handbook 296 (MLRA 133 Central Claypan Areas). Retrieved from http://soils.missouri.edu/mo_mlra/mlra113.htm

White, M.J., Storm, D.E., Busteed, P.R., Stoodley, S.H., Phillips, S.J., 2009. Evaluating Nonpoint Source Critical Source Area Contributions at the Watershed Scale. J. Environ. Qual., 38, 1654-1663.

Zollweg, J. A., Gburek, W. J., Pionke, H. B., Sharpley, A. W., 1995. GIS-based delineation of source areas of phosphorous within agricultural watersheds of the northeastern USA. Modelling and management of sustainable basin-scale water resource systems Proc. Int. symposium, Colorado, 1995, IAHS, Wallingford (England), 231, 31-39. 
664 Table 1. Criteria used to classify areas using SVI (USDA-NRCS, 2012).

Hydrologic soil group

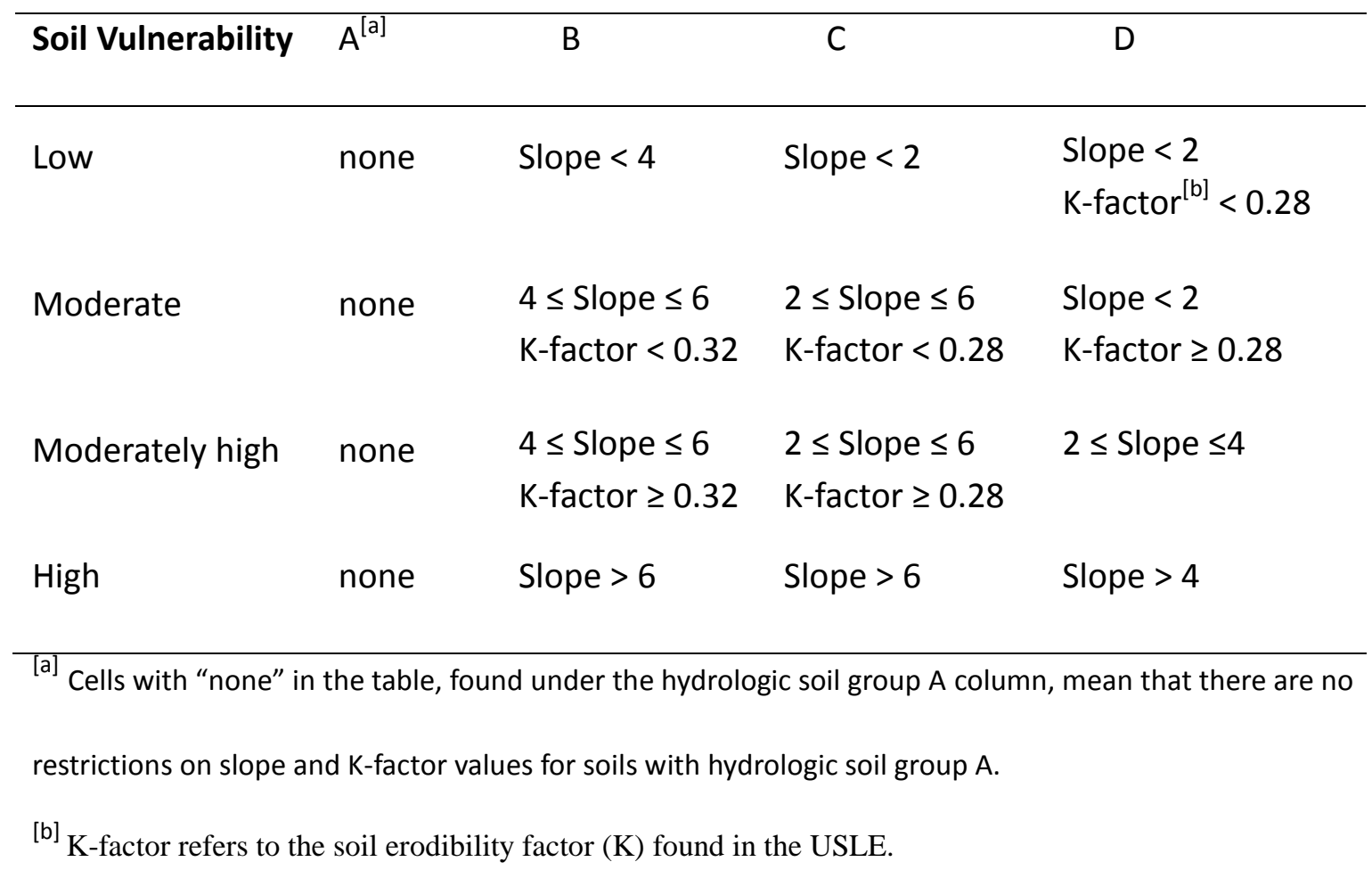

668 
669 Table 2. Watershed area classified into each vulnerability class by the SVI and CCI. Watershed area in each vulnerability class (\%)

\begin{tabular}{lcccc}
\hline Index & High & Moderately high & Moderate & Low \\
\hline SVI, SSURGO slopes & 4.1 & 51.9 & 44.0 & 0.0 \\
SVI, DEM slopes & 6.3 & 23.7 & 70.0 & 0.0 \\
CCI, SSURGO slopes & 14.3 & 62.3 & 18.1 & 5.3 \\
CCI, DEM slopes & 16.3 & 42.5 & 32.9 & 8.3 \\
\hline
\end{tabular}

670

671 
672 Table 3. Contingency table showing percentage of watershed area in agreement and 673 disagreement between SVI and CCI using DEM slopes.

High CCl Not high CCl

$\begin{array}{lll}\text { High SVI } & 5.3 & 1.0\end{array}$

Not high SVI

11.0

82.7

674

675 
676 Table 4. Distribution of slope classes determined from SSURGO and DEM in Goodwater Creek 677 Experimental Watershed

\begin{tabular}{ccc} 
& \multicolumn{3}{c}{ Slope source } \\
\cline { 2 - 3 } Slope range & \% watershed area & \% watershed area \\
\cline { 2 - 3 } $0-1$ & 14.6 & 42.0 \\
$1-2$ & 29.4 & 28.0 \\
$2-4$ & 51.9 & 23.7 \\
$>4$ & 4.1 & 6.3 \\
\hline
\end{tabular}

678

679 
680 Table 5. Contaminant loads from HRUs by vulnerability class

Mean and standard deviation ${ }^{*}$ of contaminant load

\begin{tabular}{lcccc} 
Contaminant & High & Moderately high & Moderate & Low \\
\hline Sediment (metric tons/ha) & $5.1(0.6)$ & $2.2(0.2)$ & $1.2(0.6)$ & $0.7(0.4)$ \\
Total Nitrogen (kg/ha) & $22(1.3)$ & $15(0.5)$ & $11(2.2)$ & $9(1.7)$ \\
Total Phosphorus (kg/ha) & $2.9(0.2)$ & $1.7(0.1)$ & $1.1(0.3)$ & $0.7(0.2)$
\end{tabular}

$681{ }^{*}$ The mean value is the first number and the standard deviation is in parentheses

682 
683 Table 6. Contingency tables between SVI and model results for sediment, nitrogen, and 684 phosphorus.

\begin{tabular}{|c|c|c|c|c|}
\hline \multirow[b]{2}{*}{ SVI class } & \multicolumn{4}{|c|}{ Number of HRUs in each SWAT simulated sediment loss class } \\
\hline & High & Moderately high & Moderate & Low \\
\hline High & 5 & & & \\
\hline Moderately high & & 36 & & \\
\hline Moderate & 2 & 3 & 93 & 40 \\
\hline \multirow[t]{3}{*}{ Low } & & & 1 & 3 \\
\hline & \multicolumn{4}{|c|}{ Number of HRUs in each SWAT simulated TN loss class } \\
\hline & High & Moderately high & Moderate & Low \\
\hline High & 5 & & & \\
\hline Moderately high & & 36 & & \\
\hline Moderate & 2 & & 96 & 40 \\
\hline \multirow[t]{3}{*}{ Low } & & & 2 & 2 \\
\hline & \multicolumn{4}{|c|}{ Number of HRUs in each SWAT simulated TP loss class } \\
\hline & High & Moderately high & Moderate & Low \\
\hline High & 5 & & & \\
\hline Moderately high & & 36 & & \\
\hline Moderate & 2 & 3 & 93 & 40 \\
\hline Low & & & 2 & 2 \\
\hline
\end{tabular}

685

686 
687 Table 7. Contingency table between $\mathrm{CCl}$ and model results for sediment, nitrogen, and 688 phosphorus

\begin{tabular}{rcccc}
\hline CCl class & High & Moderately high & Moderate & Low \\
\hline High & 0 & 31 & & \\
$\begin{array}{r}\text { Moderately high } \\
\text { Moderate }\end{array}$ & 7 & 8 & 95 & 42 \\
Low & & & & 42 \\
\hline
\end{tabular}

Number of HRUs in each SWAT simulated TN loss class

High High Moderately high Moderate Low

$\begin{array}{rcccc}\begin{array}{r}\text { Moderately high } \\ \text { Moderate }\end{array} & 7 & 31 & 98 & \\ \text { Low } & & 5 & \end{array}$

Number of HRUs in each SWAT simulated TP loss class

\begin{tabular}{rccr} 
& High & Moderately high & Mode \\
\cline { 2 - 4 } High & 0 & & \\
high & & 31 & \\
derate & 7 & 8 & 95 \\
Low & & &
\end{tabular}


(a)

\section{SVI Risk}

Moderate

Moderately High

Wigh

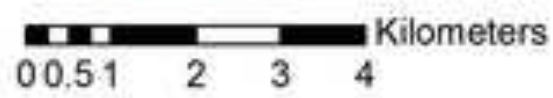


(a)

\section{SVI Risk}

Moderate

Moderately High

High

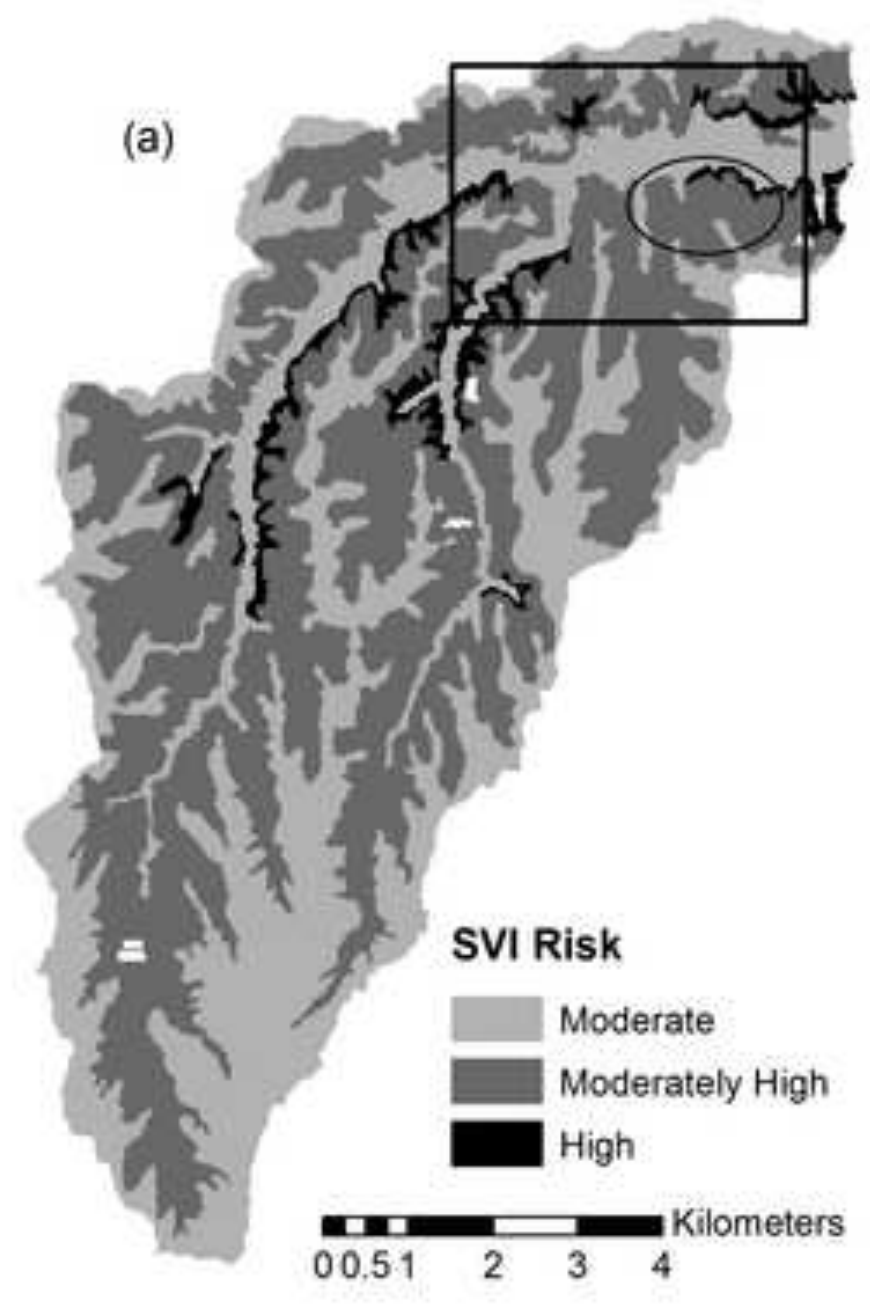




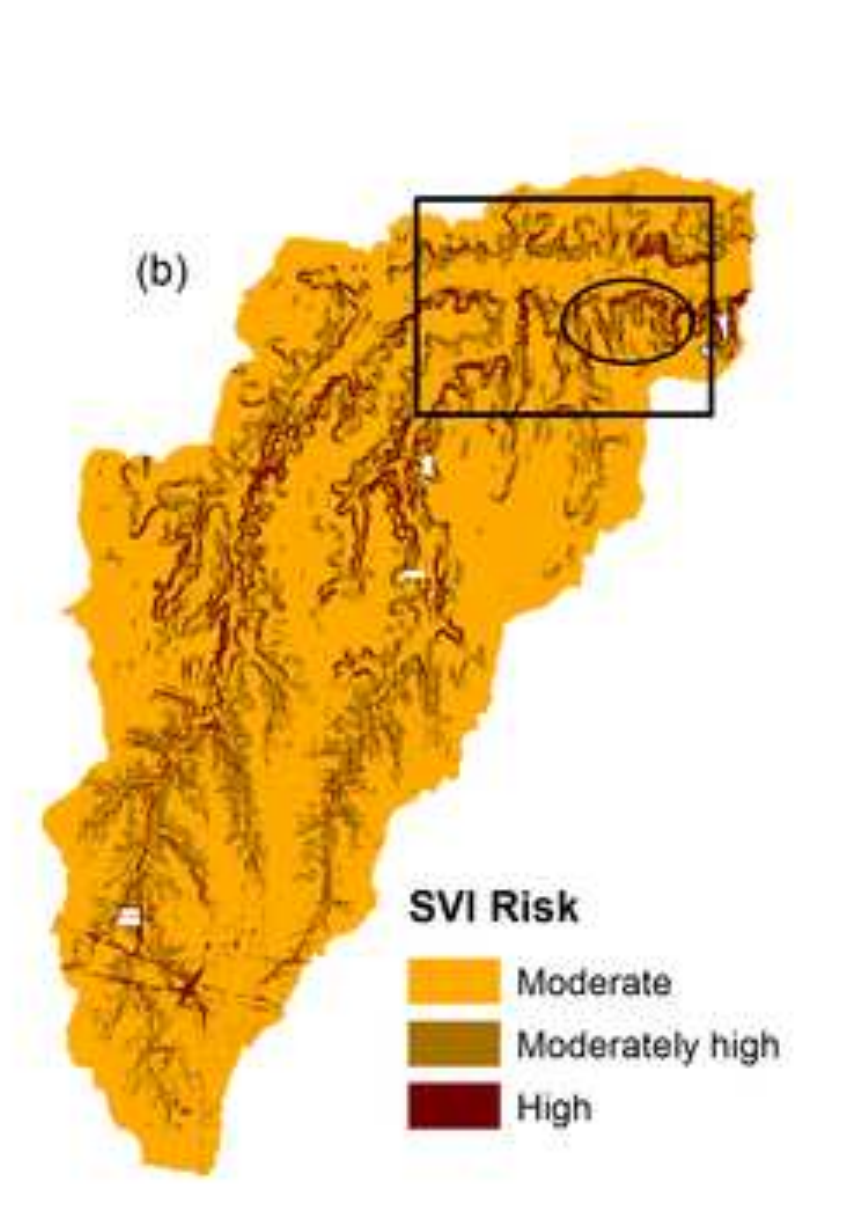

Figure2b_color

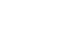

\section{,}

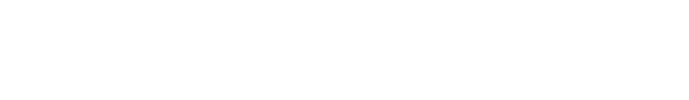

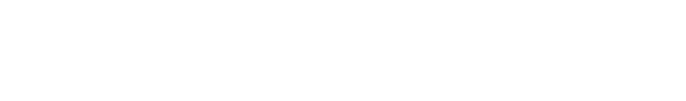
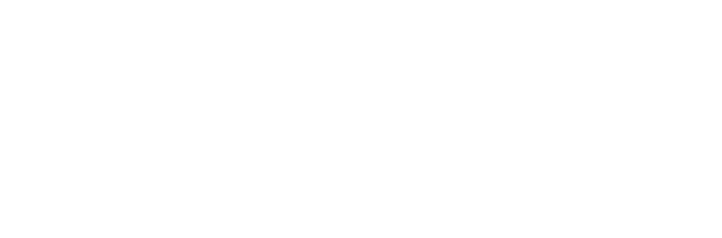

政

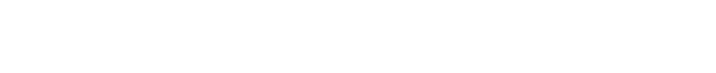

-

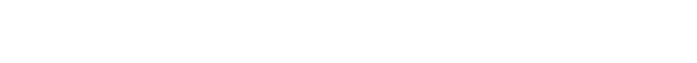

(1)
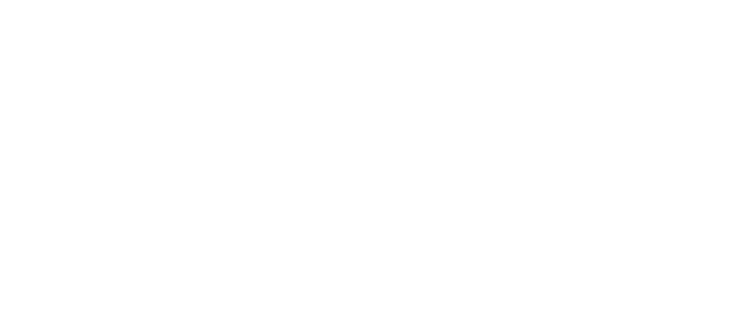


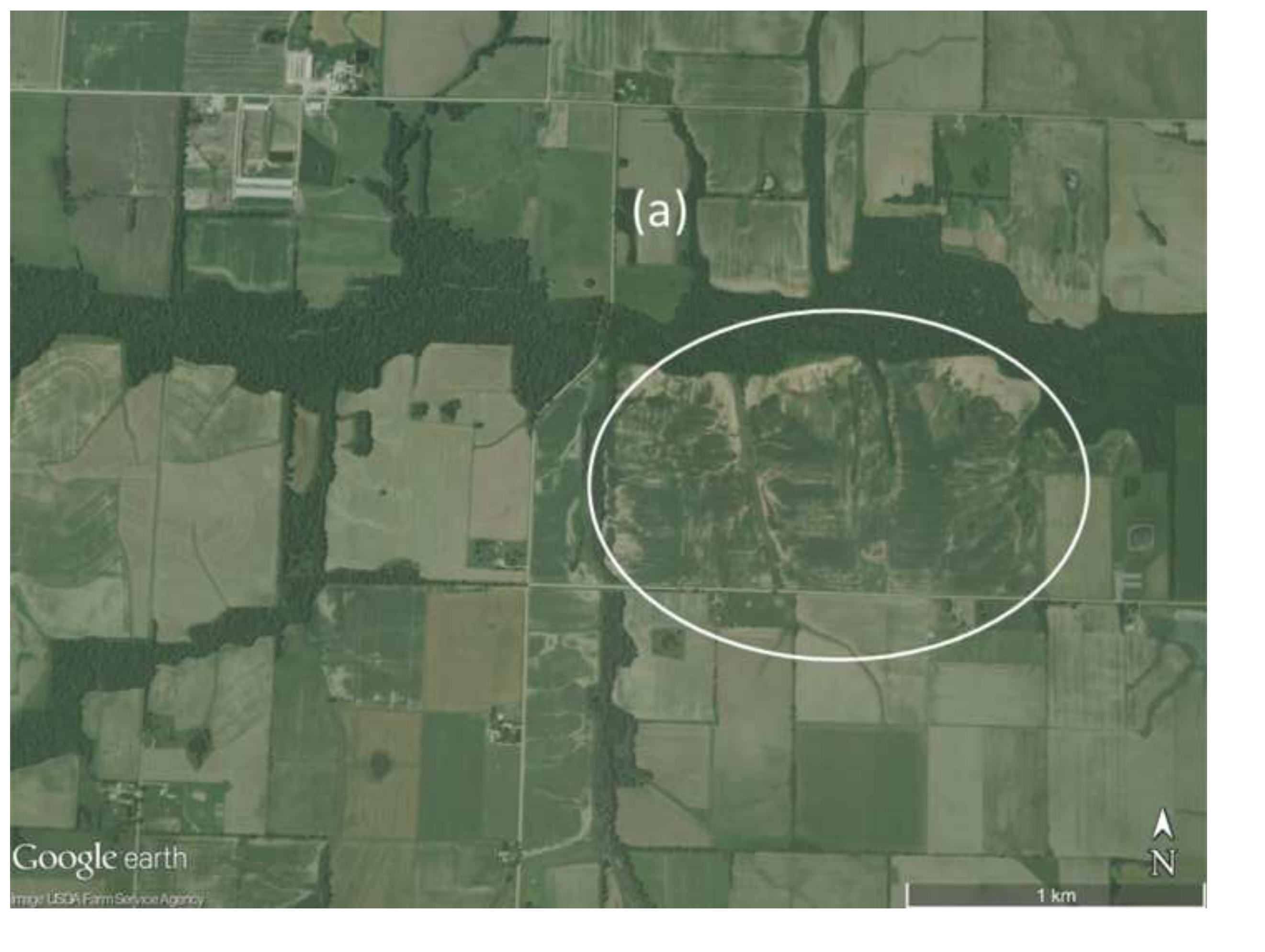

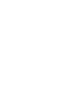
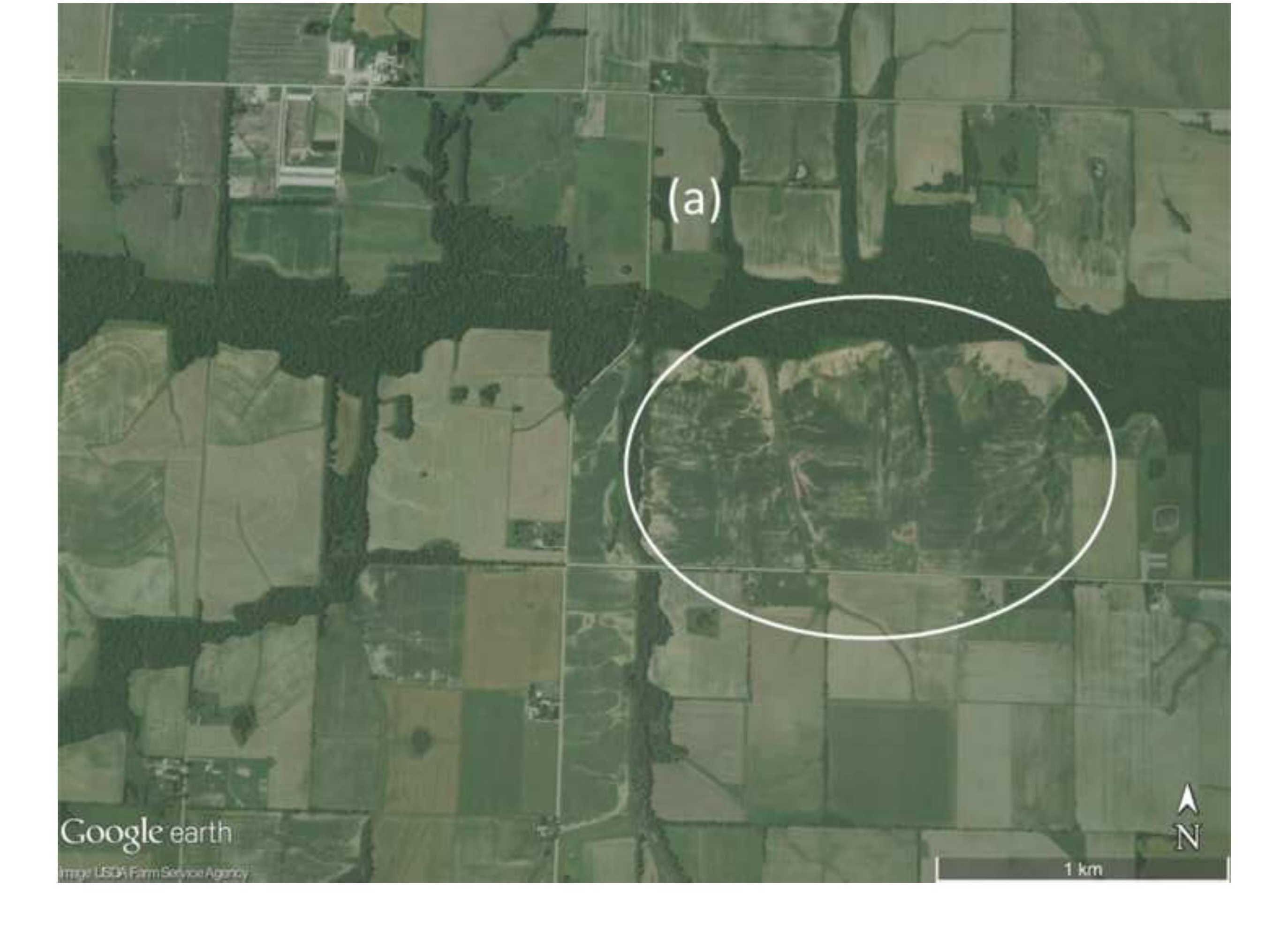


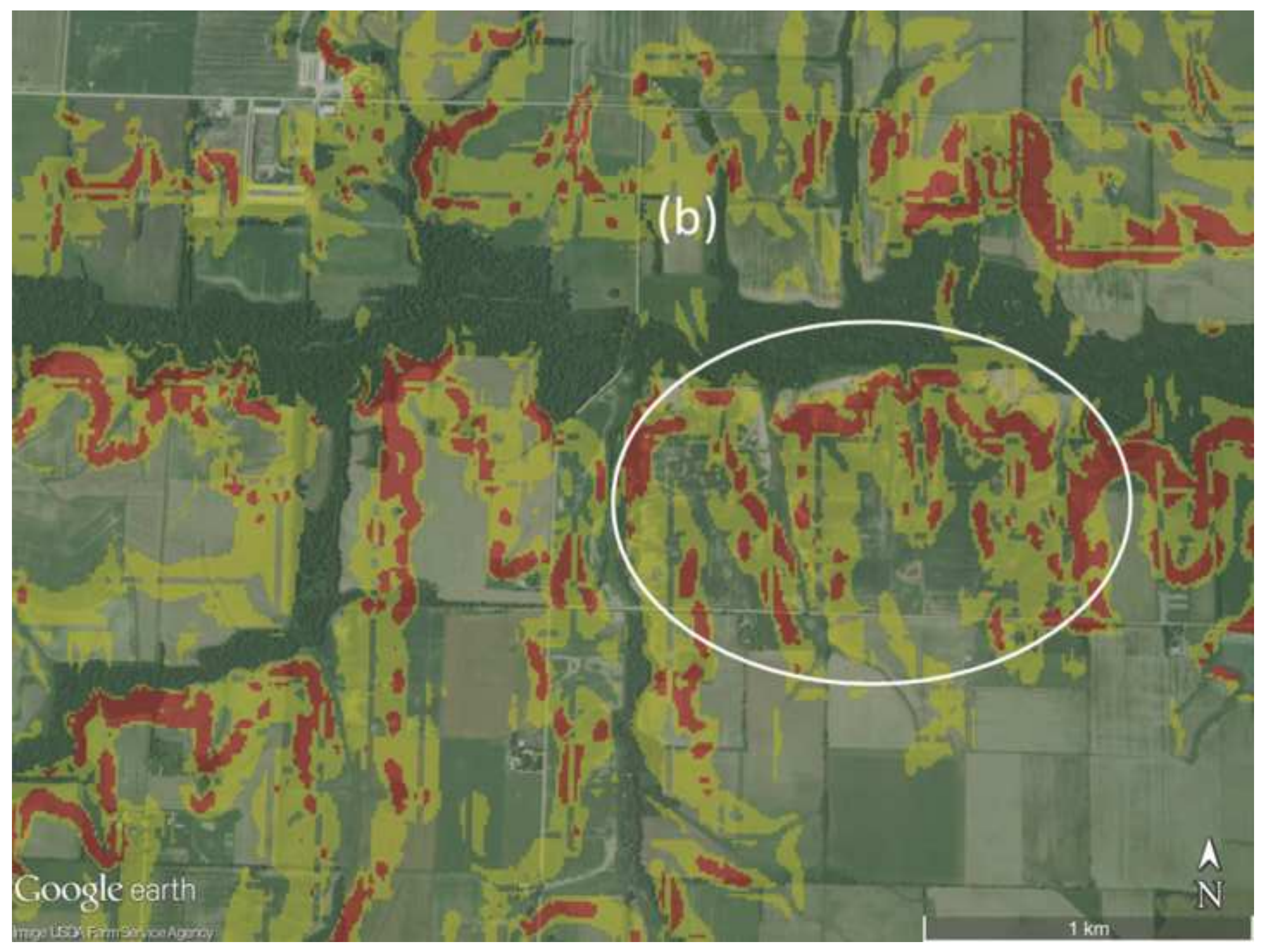




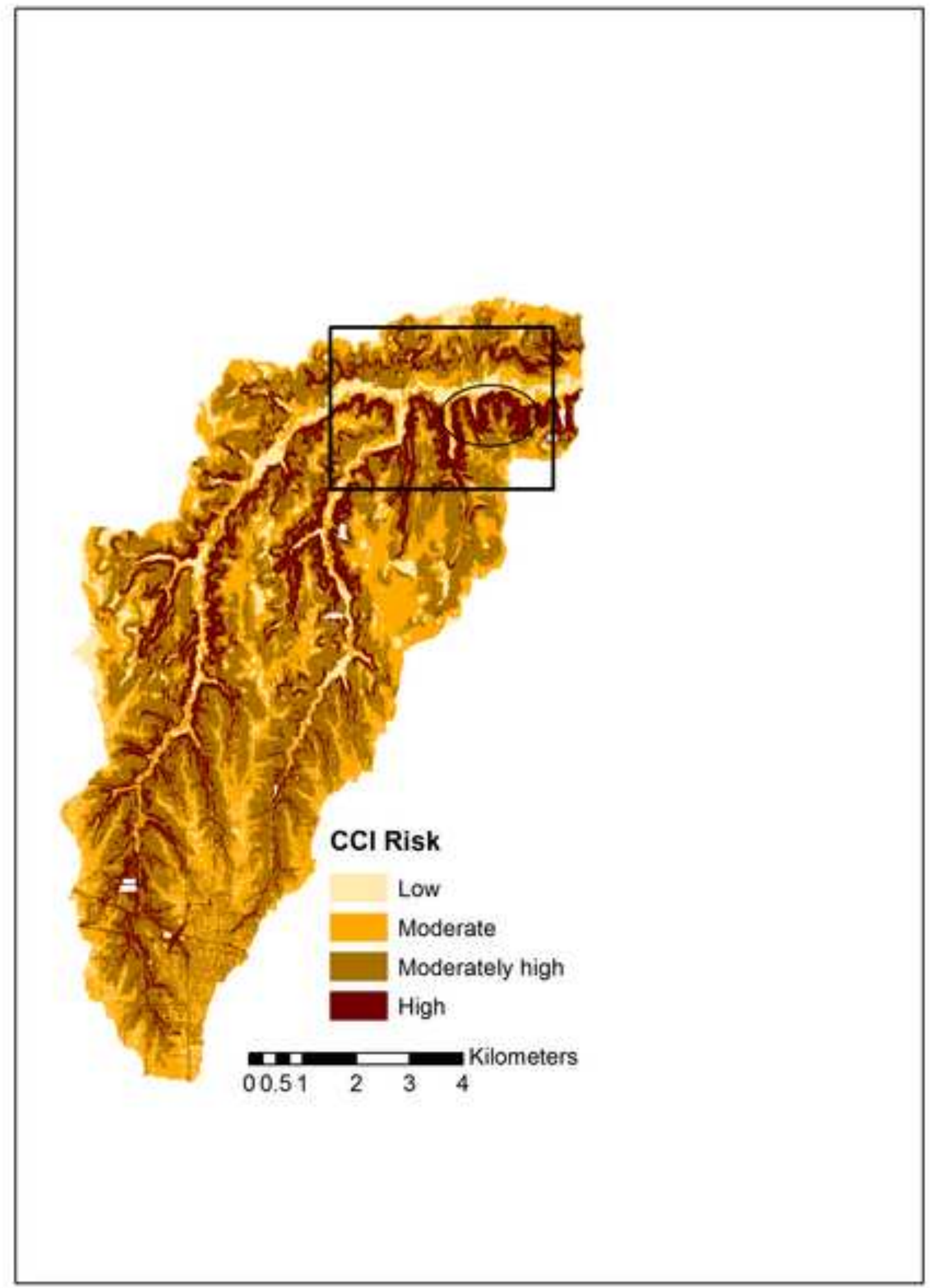

Figure4_color 


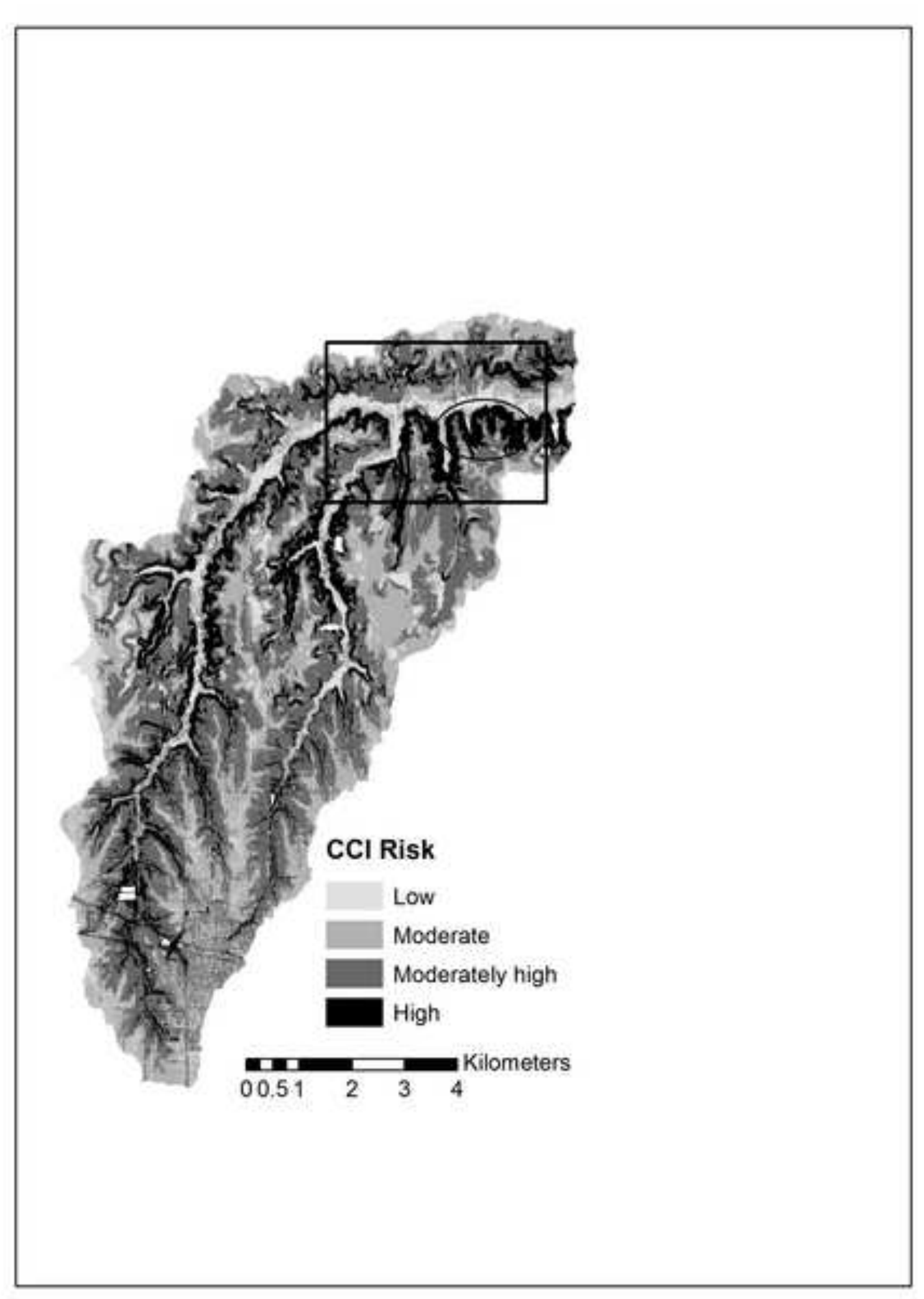

Figure4_BW

Fure4

(1)




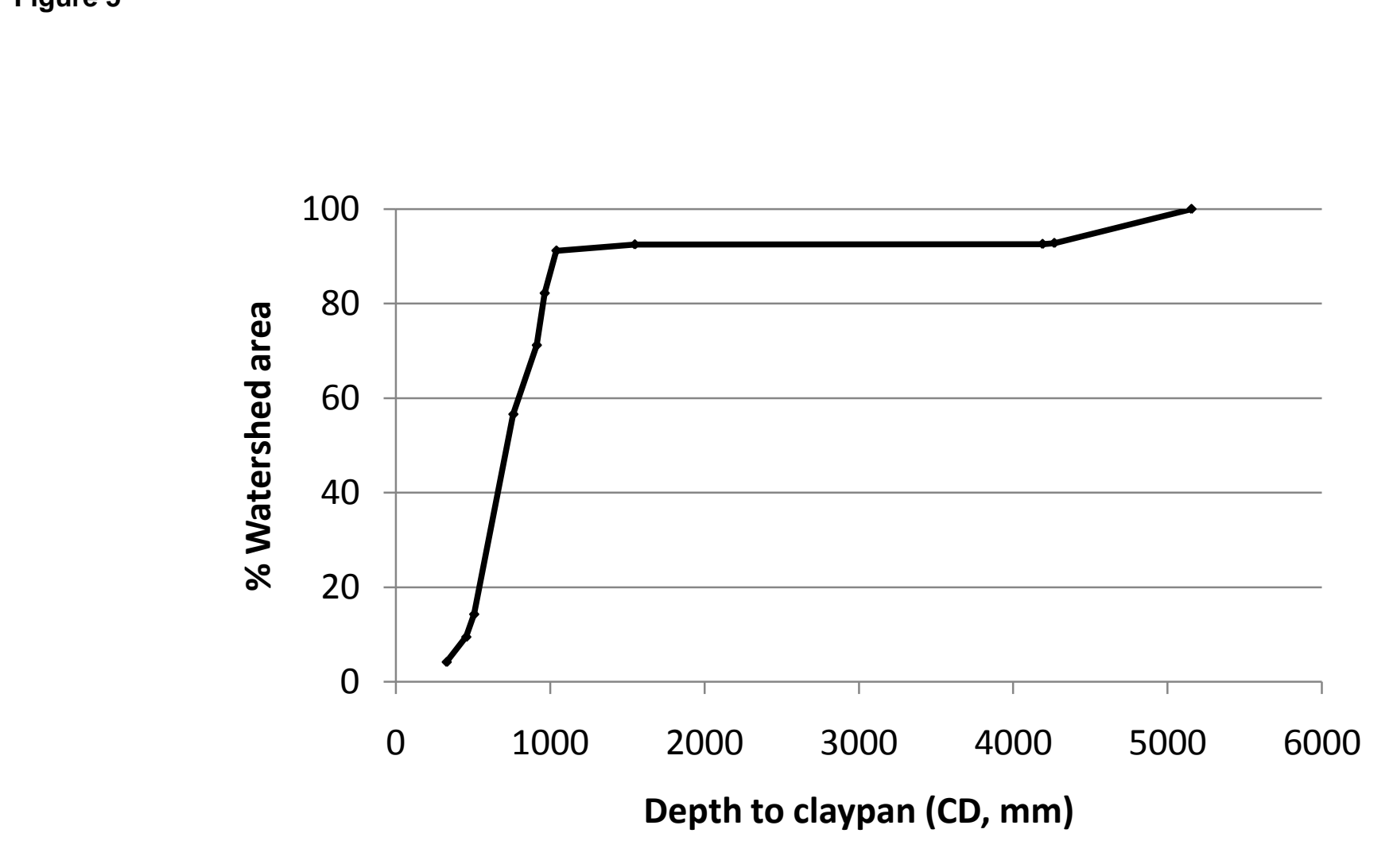

Figure 5

Depth to claypan (CD, mm)

.

.

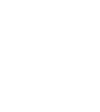

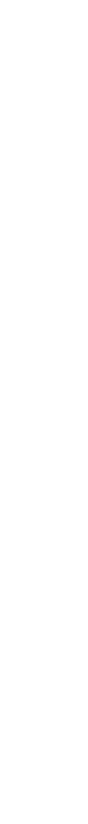




\section{Figures captions}

Fig. 1. Location of Goodwater Creek Experimental Watershed and Central Claypan Areas. The Central Claypan Areas are separated into two sections: one in Missouri and one in Illinois. The Goodwater Creek Experimental Watershed is located in the center of the Missouri section of the Central Claypan Areas. The soil map provides information about the diversity of soils as well as slopes in the watershed.

Fig. 2. Maps of SVI classifications in GCEW using (a) SSURGO and (b) DEM slopes. No area was classified as low vulnerability. When SSURGO slopes are used, the area of moderately high vulnerability was very large. The rectangle and the oval correspond to the photo shown in Fig.3.

Fig. 3. Aerial photo of a fraction of Goodwater Creek Experimental Watershed in 2009 (courtesy of the USDA Farm Service Agency and Google Earth), (a) without, and (b) with areas of high (in red) and moderately high (in yellow) vulnerability derived with DEM slopes. In the middle right of the photo (oval), soils are highly vulnerable and insufficient conservation efforts resulted in visible degradation. Fields on the left of the photo are on equally highly vulnerable soils but terraces have been installed.

Fig. 4. Map of CCl classifications in GCEW using DEM slopes. CCl produced more high vulnerability areas than SVI, all located in the footslope landscape position.

Fig. 5. Cumulative distribution of depth to claypan values in Goodwater Creek Experimental Watershed.

$\underline{\text { Notes }}$

1. Figures 2 and 3 are in two different parts. The two parts are in different files.

2. We are considering having Figures 2 and 4 in black and white or in color in the print version of the article. This will depend on the cost. Different files are provided for the black and white and the color versions. 